\title{
Weather radars - the new eyes for offshore wind farms?
}

Trombe, Pierre-Julien ; Pinson, Pierre; Vincent, Claire Louise; Bøvith, Thomas; Cutululis, Nicolaos Antonio; Draxl, Caroline; Giebel, Gregor; Hahmann, Andrea N.; Jensen, Niels E.; Jensen, Bo P. Total number of authors: 14

Published in:

Wind Energy

Link to article, DOI:

10.1002/we.1659

Publication date:

2014

Document Version

Early version, also known as pre-print

Link back to DTU Orbit

Citation (APA):

Trombe, P-J., Pinson, P., Vincent, C. L., Bøvith, T., Cutululis, N. A., Draxl, C., Giebel, G., Hahmann, A. N., Jensen, N. E., Jensen, B. P., Le, N. F., Madsen, H., Pedersen, L. B., \& Sommer, A. (2014). Weather radars the new eyes for offshore wind farms? Wind Energy, 17(11), 1767-1787. https://doi.org/10.1002/we.1659

\section{General rights}

Copyright and moral rights for the publications made accessible in the public portal are retained by the authors and/or other copyright owners and it is a condition of accessing publications that users recognise and abide by the legal requirements associated with these rights.

- Users may download and print one copy of any publication from the public portal for the purpose of private study or research.

- You may not further distribute the material or use it for any profit-making activity or commercial gain

- You may freely distribute the URL identifying the publication in the public portal 


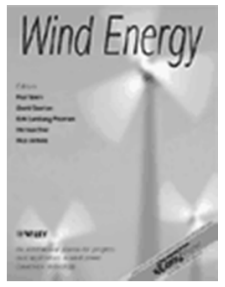

\section{Weather radars - The new eyes for offshore wind farms?}

\begin{tabular}{|r|l|}
\hline Journal: & Wind Energy \\
\hline Manuscript ID: & Draft \\
\hline Wiley - Manuscript type: & Broader Perspectives \\
\hline Date Submitted by the Author: & $\mathrm{n} / \mathrm{a}$ \\
\hline Complete List of Authors: & $\begin{array}{l}\text { Trombe, Pierre-Julien; Technical University of Denmark, DTU Informatics } \\
\text { Pinson, Pierre; Technical University of Denmark, DTU Informatics } \\
\text { Bøvith, Thomas; Danish Meteorological Institute (DMI), } \\
\text { Cutululis, Nicolaos A.; Technical University of Denmark, DTU Wind Energy } \\
\text { Draxl, Caroline; Technical University of Denmark, DTU Wind Energy } \\
\text { Giebel, Gregor; Technical University of Denmark, DTU Wind Energy } \\
\text { Hahmann, Andrea; Technical University of Denmark, DTU Wind Energy } \\
\text { Jensen, Niels E.; Danish Hydrological Institute, } \\
\text { Jensen, Bo P.; Danish Hydrological Institute, } \\
\text { Le, Nina F.; DONG Energy A/S, } \\
\text { Madsen, Henrik; Technical University of Denmark, DTU Informatics } \\
\text { Pedersen, Lisbeth B.; Danish Hydrological Institute, } \\
\text { Sommer, Anders; Vattenfall A/S, } \\
\text { Vincent, Claire; Technical University of Denmark, DTU Wind Energy }\end{array}$ \\
\hline \multirow{2}{*}{ Keywords: } & $\begin{array}{l}\text { weather radar, wind power forecasting, offshore, wind fluctuations, } \\
\text { mesoscale, Horns Rev }\end{array}$ \\
\hline \hline
\end{tabular}




\title{
2 Weather Radars - The new eyes for offshore wind farms?
}

${ }_{3}$ Pierre-Julien Trombe ${ }^{1}$, Pierre Pinson ${ }^{1}$, Thomas Bøvith ${ }^{2}$, Nicolaos A. Cutululis ${ }^{3}$, Caroline Drax $^{3}$,

${ }_{4}$ Gregor Giebel $^{3}$, Andrea N. Hahmann ${ }^{3}$, Niels E. Jensen ${ }^{4}$, Bo P. Jensen ${ }^{4}$, Nina F. Le ${ }^{5}$, Henrik

5 Madsen $^{1}$, Lisbeth B. Pedersen ${ }^{4}$, Anders Sommer ${ }^{6}$, Claire Vincent $^{3}$

$6 \quad{ }^{1}$ DTU Informatics, Technical University of Denmark, Kgs. Lyngby, Denmark

$7 \quad 2$ Danish Meteorological Institute, Copenhagen, Denmark

$8{ }^{3}$ DTU Wind Energy, Technical University of Denmark, Roskilde, Denmark

$9 \quad{ }^{4}$ Danish Hydrological Institute (DHI), Aarhus, Denmark

${ }_{10}^{5}$ DONG Energy A/S, Gentofte, Denmark

$11{ }^{6}$ Vattenfall Denmark A/S, Fredericia, Denmark

\begin{abstract}
Offshore wind fluctuations are such that dedicated prediction and control systems are needed for optimizing the management of wind farms in real-time. In this paper, we present a pioneer experiment - Radar@Sea - in which weather radars are used for monitoring the weather at the Horns Rev offshore wind farm, in the North Sea. First, they enable the collection of meteorological observations at high spatio-temporal resolutions for enhancing the understanding of meteorological phenomena that drive wind fluctuations. And second, with the extended visibility they offer, they 12 can provide relevant inputs to prediction systems for anticipating changes in the wind fluctuation dynamics, generating improved wind power forecasts and developing specific control strategies. However, integrating weather radar observations into automated decision support systems is not a plug-and-play task and it is important to develop a multi-disciplinary approach linking meteorology and statistics. Here, (i) we describe the settings of the Radar@Sea experiment, (ii) we report the experience gained with these new remote sensing tools, (iii) we illustrate their capabilities with some concrete meteorological events observed at Horns Rev, (iv) we discuss the future perspectives for weather radars in wind energy. Copyright (c) 2012 John Wiley \& Sons, Ltd.
\end{abstract}

Wind Energ. 2012; 00:2-40 (c) 2012 John Wiley \& Sons, Ltd. 
Weather radar; wind power forecasting; offshore; wind fluctuations; mesoscale; Horns Rev

DOI: 10.1002/we

\section{INTRODUCTION}

\section{Correspondence}

Lyngby, Denmark

E-mail: pjt@imm.dtu.dk

Received ...

Pierre-Julien Trombe, DTU Informatics, Technical Univsersity of Denmark, Richard Petersens Plads (bdg. 305), DK-2800 Kgs.

A substantial number of large-scale offshore wind farms have been deployed in Northern Europe over the last few years, and the plan is to keep on expanding offshore wind power in the near future [1]. Along that expansion, the development of specific methodologies for wind resource assessment in offshore environments has received much attention. In particular, the use of remote sensing techniques has led to significant advances in that domain [2]. In comparison, much less attention has been given to operational issues linked to the predictability and controllability of these large offshore wind farms [3]. And yet, the potential magnitude of wind fluctuations is such that advanced control strategies are indispensable and have to be performed in real-time [4], even more when weather conditions become extreme [5]. Offshore wind power fluctuations also induce additional challenges for Transmission Systems Operators (TSO) in maintaining the balance between electricity production and demand [6]. For these applications, the availability of accurate wind power forecasts is a prerequisite. In particular, there is a large consensus on the growing importance of such forecasts at specific temporal resolutions of 5-10 minutes, and look-ahead times of a few hours [7].

Short-term wind power forecasts, from a few minutes up to a few hours, are preferably generated with statistical models using historical data. However, today, operational prediction systems for offshore wind farms are not fundamentally different than for onshore wind farms [8]. They traditionally rely on meteorological forecasts (e.g., wind speed and direction) whose temporal resolution is usually between 1 and 3 hours, and up to a forecast length of 48-72 hours. This acts as a limitation when it comes to capturing the intra-hour volatility of offshore wind power fluctuations induced by meteorological phenomena in the boundary layer, even more when meteorological forecasts are misleading (e.g., phase errors). Furthermore, it is a well-known issue that the layout of offshore wind farms, concentrating a high density of 
2

wind turbines within a small geographical area, makes the impact of local meteorological phenomena on their power production stronger than at onshore sites where smoothing effects occur. These issues were addressed in several recent studies which alternatively proposed the use of regime-switching models [9, 10], a new type of predictive density [11], or local wind speed and direction measurements as new inputs [12]. However, even though these models give evidence of their interesting predictive power, their ability to accurately predict the most severe fluctuations remain very limited and offshore wind power forecasts are characterized by large uncertainties. This also highlights the limitations of local wind measurements (e.g., from nacelle anemometry and SCADA systems) when it comes to upcoming changes in weather conditions on spatial scales of kilometers. Meteorological observations that cover a broader spatial area are thus required, not only to improve our understanding of the phenomena driving mesoscale wind fluctuations, but also to provide more informative inputs to prediction models.

In wind power forecasting, there is a need for new and multi-disciplinary approaches combining the expertise of meteorologists, forecasters, control engineers and wind farm operators. This is the idea developed in an ongoing experiment - Radar@Sea - which proposes the use of weather radars, novel remote sensing tools in wind energy, for the online observation of the atmosphere at offshore sites. This experiment is motivated by recent advances in the modeling of wind fluctuations at Horns Rev, Denmark, and the identification of several climatological patterns correlated with periods of increased wind speed variability, for time scales from 10 minutes up to 1 hour [13]. In particular, precipitation and large wind speed fluctuations are often observed simultaneously. Weather radars are the ideal tools to detect, locate and quantify precipitation. They have become essential tools in real-time decision support systems for tracking and predicting natural hazards. More generally, owing to their techniques, they offer an extended visibility of the weather conditions over substantially large areas. Therefore, they have the potential for anticipating the arrival of weather fronts and other meteorological phenomena which intensify offshore wind fluctuations. It is even more important for some offshore wind farms that cannot benefit from upwind information, being the first hit by the onset of particular weather regimes.

The experiment we present in this paper is the first of this type for wind energy applications worldwide, to our knowledge. Yet, lessons learnt from the use of weather radars in hydrological and meteorological sciences show that integrating weather radar observations into automated decision support systems is not a plug-and-play task. The volume and complexity of weather radar observations are such that specific diagnosis tools have to be developed for data quality control, data visualization and feature extraction (see, for instance, [14] for a detailed description of the WDSS-II system for severe weather nowcasting). Therefore, a thorough understanding of the weather radar techniques, capabilities and limitations, as well as the field of application are expected to influence the design of the final decision support system. 
67 For those reasons, we think that the experience gained through the Radar@ Sea experiment could be a valuable source of

information to other researchers following a similar approach.

The structure of this paper is as follows. In section 2, we give an introduction to the meteorological conditions (precipitation and wind fluctuations patterns) over Denmark and the North Sea. In section 3, weather radars principles, capabilities and limitations are presented. In section 4, we describe the Radar@ Sea experiment along with the two weather radar systems used for the experiment. In section 5, we show four precipitation events and analyze how they relate to wind speed and wind power fluctuations observed at Horns Rev. In section 6, we discussed the future perspectives for weather radars in wind energy applications. Finally, section 7 delivers concluding remarks.

\section{METEOROLOGICAL CONTEXT}

Automating the integration of complex and large meteorological observation sets into prediction systems requires a preliminary understanding of the meteorological phenomena over the region of interest, both at the synoptic scale and the mesoscale. More specifically, we are interested in using precipitation observations as indicators for weather conditions featuring high wind variability. Therefore, a clear view on the relationship between meteorological variables and the development of precipitation is likely to help interpreting weather radar observations. In this section, the focus is placed on the coastal area of Denmark and, in particular, the North Sea.

\subsection{Synoptic scale}

Denmark is located at the border between the North Sea and the European continent. The atmospheric circulation patterns are dominated by westerly flows coming from the Atlantic Ocean and the North Sea. The average wind direction can often be associated with particular weather conditions, and each weather phenomenon has a unique signature in terms of the local wind variability, precipitation and small scale weather.

For example, cold fronts, which are the boundary between cold and warm air masses, approach the North Sea from the west and are usually associated with a wind direction change from southwesterly to northwesterly. In the winter months, anticyclones over the region often bring cold, clear conditions and light easterly winds, while in the summer months, anticyclones tend to be positioned further to the south and bring warm, sunny weather and still wind conditions. West and South-West are the prevailing wind directions while North and North-East directions are the least frequent [15]. A brief summary of the most frequent weather types and their associated precipitation patterns is provided in Table I, conditioned 


\section{WEATHER RADARS}

Remote sensing tools have enabled the collection of large amounts of meteorological data and their importance for the development of wind energy projects is constantly growing [20]. For instance, ground-based tools such as LiDAR and SoDAR are used for estimating wind profiles at high heights. Alternatively, LiDAR can be mounted on a wind turbine hub or rotating spinner to measure the approaching wind flow in view of optimizing wind turbine control [21, 22]. Airborne radars can contribute to the observation of wake effects at large offshore wind farms, and offshore wind maps can be generated from satellite observations [23]. However, applications of remote sensing tools in wind energy often converge towards a common goal, which is an improved assessment of the wind resource. In addition, their outputs tend to be either spatially limited (e.g., LiDAR and SoDAR) or temporally sparse (e.g., satellite observations). In contrast, one of the clear strengths of weather radar systems is their superior capacity to generate observations at high resolutions, both in time and space, which is a very desirable capability for the short-term forecasting of wind power fluctuations. In this section, we provide some insights on weather radar principles, capabilities and limitations which are further illustrated by concrete examples taken from Radar@ Sea in the subsequent sections.

\subsection{Principles \& Capabilities}

Weather radars are airborne or ground-based remote sensing tools. In this paper, we only deal with ground-based weather radars. The data acquisition process consists of a circular and volumetric scanning of the atmosphere. Microwave radiation is emitted and reflected by precipitation particles. Data collected by weather radars correspond to quantitative estimations of precipitation reflectivity. Precipitation intensity estimation can be obtained through the so-called Z-R relationship [24].

The volumes scanned are traditionally summarized to deliver standardized output displays such as images of precipitation reflectivity at different altitudes. For a technical introduction on weather radars, we refer to [25].

There exist a wide variety of weather radars and their specificities depend on their wavelength: X-Band, C-Band or SBand for the most common ones (listed here from the shortest to the longest wavelength; from $3.2 \mathrm{~cm}$, to 5.4 and $10 \mathrm{~cm}$ ). Typically, the longer the wavelength, the further away the radar waves can travel in the atmosphere and detect precipitation. S-Band radars have an operational range beyond $450 \mathrm{~km}$ and are preferably used for severe weather monitoring (e.g., forecasting of environmental hazards such as flash floods and tornadoes; tracking of severe meteorological events such as thunderstorms and lightnings) [26], C-Band radars operate up to 200-300 km and are often used for quantitative precipitation estimation for monitoring river catchment or urban drainage systems, whereas X-Band radars have a range within $100 \mathrm{~km}$ and are useful for local applications. The reason for the difference in the applicable range is that at lower 
- Radar waves can be intercepted, reflected or even completely blocked by non-meteorological targets such as ground, sea, buildings, mountains, etc. This problem is referred to as clutter. In this regard, the choice of an appropriate site for installing a weather radar is crucial as it reduces the risk of clutter;

- Short wavelength radars (e.g., X-Band) can be affected by beam attenuation problems in case of intense precipitation, resulting in the quality of the measurements altered at far ranges and, more specifically, large underestimation of precipitation reflectivity;

- Specific atmospheric conditions (e.g., inversion of the vertical temperature or moisture gradient in the atmosphere) may cause anomalous propagation of the radar waves which are super-refracted and bent towards the ground or the sea instead of propagating in the atmosphere;

- During convective events, the scale of precipitation cells may be relatively small compared to the volume scanned by weather radars, resulting in underestimating precipitation reflectivity, this problem is known as beam filling and become more serious at far ranges;

- Due to the curvature of the Earth, the height at which radar waves propagate increases with the range, leading to potential underestimation of near surface precipitation at far ranges, this problem is known as overshooting.

Furthermore, a growing source of concerns regarding measurement accuracy is linked to the deployment of wind farms nearby weather radar installations, generating large clutter [30]. In particular, wind farms echoes are comparable to those of small storm cells. The larger the wind farm, the larger the area and the strength of the clutter are. The closer the weather radar and wind farm are, the further away the problems propagate. Impacts of wind turbines on weather radar observations can even be identified at far ranges, up to $100 \mathrm{~km} \mathrm{[31].}$

\section{THE RADAR@SEA EXPERIMENT}

Radar@Sea, the first experiment involving weather radars for offshore wind energy applications, started in 2009 and is expected to run until the end of the year 2012. It consisted of the installation, operation, and maintenance of a Local Area Weather Radar (LAWR) based on X-Band technology, at the offshore site of Horns Rev, Denmark. Observations from a nearby Doppler C-Band weather radar were used to complement the initial data set. Finally, wind speed, wind direction and wind power measurements from the HR1 wind farm came to complete what is by now a unique data set in the wind energy community. The respective geographical locations and spatial coverage of the two radars and the HR1 wind farm are shown in Figure 2. 


\subsection{Local Area Weather Radar}

The LAWR is installed on the roof of the accommodation platform of the Horns Rev 2 (HR2) wind farm (see Figure 3), in the North Sea, about $20 \mathrm{~km}$ off the West coast of Jutland, Denmark. The LAWR is a light configuration weather radar system, ideal for remote locations (see [32] for a complete presentation of the system). The data collection campaign with the LAWR started in 2010. The LAWR is located $19 \mathrm{~km}$ away from HR1 and is run with a coverage range of 60 $\mathrm{km}$. In order to produce one image, 24 continuous scans are performed every minute with a large vertical opening angle of $\pm 10^{\circ}$ and a horizontal opening of $1^{\circ}$. One specificity of the LAWR is that is does not generate direct observations of precipitation reflectivity but, instead, dimensionless count observations (Integer values of range 0-255) that can be converted to precipitation intensity through rain gauge calibration. A sample image generated by the LAWR can be seen in Figure 4(b). For a summary on the operational settings of the LAWR, see Table II.

In the course of the Radar@ Sea experiment, the observational capabilities of the LAWR have been challenged by several problems. First, it is important to mention that the accommodation platform of the HR2 wind farm, where the LAWR is currently installed, performs many functions other than the LAWR. The result is that, even though the best possible spot on the platform was chosen, there is a large blocking of the beam and observations are not available for southwesterly azimuths (see Figure 4(b)). Second, the very close proximity of the wind turbines of HR2 contributed to large uncertainties in the measurements at close ranges. Third, due to the shared utilization of the LAWR with another experiment for wave monitoring, its mechanical clutter fence was removed. This important component usually ensures that only the reflected energy corresponding to the upper $10^{\circ}$ of its vertical opening angle is kept for precipitation sampling. The modification resulted in the measurements being contaminated by sea clutter. On the images, this translates into "dry" pixels having values between 70 and 100, instead of values closer to 0 . These problems could easily be avoided if, as part of the design of the platform in the future, a specific spot was allocated for installing measuring instruments. Last but not least, the extreme weather conditions experienced at Horns Rev presented a difficult test for the robustness of the LAWR. Passages of many storms over Denmark were recorded in the winter 2011, with mean wind speeds approaching $30 \mathrm{~m} \mathrm{~s}^{-1}$, coupled with strong gusts. Running the LAWR during these storms increased the number of rotations of its antenna from 24 to 33 39 rotations per minute, thereby increasing the risk of damaging its structural components. To circumvent that problem, an electronic breaking system was added and has, since then, proved its efficiency, enabling data collection during the subsequent storms. 


\subsection{Rømø weather radar}

The Doppler C-Band weather radar used in the Radar@Sea experiment is located in Røm $\varnothing$, Denmark, and operated by DMI, the Danish Meteorological Institute (see [33] for an introduction on the Danish weather radar network). It is located $57 \mathrm{~km}$ away from the HR1 wind farm and has a coverage range of $240 \mathrm{~km}$. Observations were collected using a 9 elevation scan strategy $\left(0.5^{\circ}, 0.7^{\circ}, 1^{\circ}, 1.5^{\circ}, 2.4^{\circ}, 4.5^{\circ}, 8.5^{\circ}, 13^{\circ}, 15^{\circ}\right)$ every 10 minutes (see Table II). Raw reflectivity measurements were converted into decibel of reflectivity $(\mathrm{dBZ})$ since it is a more appropriate unit for processing reflectivity images, as demonstrated in [34]. A sample image generated by the Doppler C-Band weather radar can be seen in Figure 4(a). The observations DMI provided us with consist of a 1-km height pseudo-CAPPI (Constant Altitude Plan Position Indicator) image product. The images which in our case have a grid spacing of $2 \mathrm{~km}$ display the radar reflectivity at an altitude of $1 \mathrm{~km}$ by selecting reflectivity from the most appropriate elevation. At ranges further than approximately $80 \mathrm{~km}$ where the beam of the lowest elevation exceeds $1 \mathrm{~km}$ altitude, data from the lowest elevation are used (hence the "pseudo"-CAPPI). A general pixel-wise interpretation of reflectivity values considers background noise echoes (birds, insects, etc.) to be between 0 and $10 \mathrm{dBZ}$, light precipitation systems (e.g., stratiform rainfall) between 10 and $30 \mathrm{dBZ}$ and the threshold for convective precipitation systems is often set to between 30 and $40 \mathrm{dBZ}$. This pixel-wise interpretation is only to be used as a simple heuristic and the characterization of radar reflectivity echoes in terms of precipitation types is a much more complex task that requires the use of advanced algorithms [35].

In its weather monitoring and forecasting activities, weather radar data are used by DMI and its partners for an increasing number of applications. This implies an increased work on data quality control procedures to improve the observation of precipitation and to mitigate the influence of radar clutter.

\subsection{Towards validating the experiment}

The experimental part of the project is not limited to the data collection. There are also a substantial number of necessary steps for validating these data, transforming them into ready-to-use products and, more generally, automating their integration into a decision support system. A preliminary step consists of performing a quality control of the data. This operation is necessary for evaluating the level of uncertainty associated with the data and defining appropriate strategies to process them. As explained in section 3, the uncertainty comes from two different sources. One is inherent to weather radar techniques (e.g., limitation for observing near surface precipitation) and the other may be caused by non-meteorological factors (e.g., clutter). In practise, the effects of the latter problems are easier to detect since measurement artifacts are not random and exhibit well-determined statistical signatures. Ideally, artifact detection methods should be robust, in 
the statistical sense, as they have to accommodate for levels of uncertainty that are changing over time. In Radar@Sea,

Wind Energ. 2012; 00:2-40 (C) 2012 John Wiley \& Sons, Ltd. seasons are given Table I. analysis methods accordingly.

\subsection{Summer storms}

\section{ILLUSTRATIVE METEOROLOGICAL EVENTS FROM HORNS REV}

In this section, we analyze four meteorological events which show the development and passage of precipitation systems in relation to wind fluctuations at the HR1 wind farm. These events were selected to illustrate the variety of situations that weather radar can help observing. We do not attempt to make any projection related to forecasting issues. Normalized wind power fluctuations at HR1 are also included in order to show their corresponding amplitude during these events. Wind speed, direction and power measurements were collected from the nacelle anemometry and SCADA systems [4]. To be consistent with section 2, we consider that there are only two seasons in Denmark, a summer or warm season from April to September, and a winter season from October to March. The prevailing synoptic conditions for each of these two

Note that non-meteorological information has not been perfectly cleaned from the displayed images. Let us acknowledge that removing measurement artifacts with automated algorithms is a highly complex task. In particular, there is always a risk of also removing valuable meteorological information by being too aggressive on the detection criteria. Our approach is to reduce the amount of non-meteorological information down to an acceptable level and adapt the robustness of image

The first meteorological event as seen by the Rømø weather radar and wind observations is shown in Figure 5. It is from July 2010 and depicts how the development of typical summer storms driving warm and moist continental air coming from the South relates to wind speed and wind power fluctuations at the HR1 wind farm. The arrows show the wind direction recorded at HR1. (1) It begins with a case of anomalous propagation falsely suggesting the presence of precipitation. This problem is likely to be caused by a temperature or moisture gradient inversion in the vertical stratification of the atmosphere (see Appendix A). (2) The problem is persistent for several hours and also visible on the right part of the second image 
which shows the development of strong convection. One can notice a storm in the proximity of the HR1 wind farm. It is delimited by a cluster of pixels with high reflectivity values exceeding $40 \mathrm{dBZ}$. That storm is embedded into a larger precipitation system. The birth and growth of that storm precede the occurrence of a strong wind gust at HR1 quickly followed by a large drop of wind speed. After that, precipitation dissipates until the development of a larger storm, one day later. (3-5) The passage of that second storm across HR1 is coupled with very large wind fluctuations. These fluctuations are likely to be caused by the strong updrafts and downdrafts associated with this type of storms [36]. Over the 5 days of this events, the wind exhibits a very chaotic behavior, with sudden and frequent changes of direction. Another interesting aspect of this event is that it illustrates a case of high wind variability coupled with medium mean wind speeds. In terms of wind power fluctuations, the passage of the first storm translates into a sudden drop of power from the rated power of HR1 to 0 within 2-3 hours. The passage of the second cluster of storms generates fluctuations of an amplitude equivalent to $50 \%$ the rated power of HR1, over a period of 8 hours.

\subsection{A cold front in the winter}

The second event is shown in Figure 6 and is from December 2010. It illustrates the passage of a cold front over the North Sea and across the HR1 wind farm during the winter. Let us recall that the North Sea surface is warmer than the lower part of the atmosphere at that time of the year, enhancing the development of strong convection [13]. (1) It starts with a shift in wind direction at HR1, from the North-East to the South-West, and smoothly increasing wind speed as the front approaches. Meanwhile, light and widespread precipitation is moving from the North-West. (2) Wind fluctuations intensify as the cold front passes across HR1 until a large negative gradient of wind speed is sensed in the transition zone of the front, behind its leading edge. The front leading edge is marked by an area of high reflectivity, between 30 and 40 $\mathrm{dBZ}$, indicating the development of convection. This area of convection is embedded into a larger area of precipitation, characterized by intermediate mean reflectivity. (3-5) In the wake of the front, the wind direction shifts from the South-West to the North-West. In addition, large wind fluctuations are sensed at HR1 simultaneously with the passage of many scattered precipitation cells. These cells are small and are characterized by very short lifetime, growing and decaying within a few hours. Inspecting satellite pictures corresponding to this events reveals well developed open cellular convection covering part of the North Sea. Wind fluctuations have an average period of around 1-2 hours, which is consistent with the spatial scale of the open cellular convection, as discussed in [18]. Resulting wind power fluctuations reach an amplitude of almost $80 \%$ the rated power of HR1, within one hour. 
Wind Energ. 2012; 00:2-40 (C) 2012 John Wiley \& Sons, Ltd. 


\section{DISCUSSION ON FUTURE PERSPECTIVES FOR WEATHER RADARS IN WIND ENERGY}

The most common fields of application of weather radar data include hydrology and weather surveillance. Consequently, most of the methodologies for analyzing weather radar data are centered on issues such as the conversion from precipitation reflectivity to intensity, or natural hazard nowcasting. In Radar@ Sea, the approach we aim at developing is inspired by existing approaches for storm tracking. However, Radar@Sea is just one among other potential wind energy applications of weather radar data. In this section, we describe the future lines of work in Radar@Sea and also discuss the future perspectives for weather radars in wind energy.

\subsection{Automating the integration of weather radar observations into a real-time wind power prediction system}

Raw weather radar data are useful to meteorologists for diagnosing precipitation systems and their respective severity by visual assessment. However, as the amount of data increases, making consistent decisions becomes more lengthy and difficult. Hence, the real value of weather radar observations can only be obtained through their integration into automated decision support systems (see [14] and references therein). Automating a decision support system requires that one or several experts determine a series of rules or criteria to be fulfilled in order to make consistent decisions. Furthermore, the system should also have the capability to learn by itself, in a closed-loop, through the acquisition of new data and experience with potential new events never observed before. For these purposes, it is important to understand the weaknesses and strengths of the weather radar system providing the data.

In Radar@Sea, a clear weakness of the two weather radars is their limited range visibility which is inherent to single weather radar systems, as opposed to networks of radars which cover much larger areas. Note that small range visibility does not mean small temporal visibility. A small range visibility translates into potential difficulties for observing the full extent of precipitation systems in real-time, since weather radars may only observe them partially. For instance, an illustrative example is to compare the second and third events in section 5. At the beginning of both events, convection develops within a relatively large precipitation field. Before and until the time the convective part of the precipitation system reaches the HR1 wind farm, it is not possible to observe what type of weather (i.e., precipitation or not) is developing in its wake, out of the range of the weather radar. In the second event, small precipitation cells corresponding to well developed open cellular convection follow whereas, in the third event, precipitation dissipates. With information on upcoming precipitation available at longer range, severe phenomena could likely be anticipated with a higher accuracy. 
Furthermore, in meteorology, there is a long tradition in assimilating data into NWP models for generating improved meteorological forecasts [41]. A reason for assimilating weather radar data into NWP models is that a fully statistical approach (i.e., weather radar data exclusively and directly used as inputs to statistical models) would likely bound its forecast skill to lead times within 3 hours whereas the requirements for integrating wind power and, more generally, renewables into power systems are such that accurate forecasts are needed, not only for the next 3 hours, but for much longer horizons. In that respect, the forecast improvement resulting from data assimilation into mesoscale NWP models could be substantial up to 12-24 hours ahead. Even though there are many issues to overcome for assimilating weather radar data into high resolution NWP models [42], encouraging results were already obtained in some particular case studies where Doppler observations were used for initializing these models [43].

\subsection{Future perspectives on improving offshore wind farm predictability and controllability}

A wealth of statistical models have been proposed for the very short-term forecasting of wind power fluctuations but, in practise, simple and parsimonious models remain difficult to outperform [8]. For the specific case of offshore wind fluctuations, most research studies have focused on the development of regime-switching models and their application for generating one step-ahead forecasts, with lead times between 1 and 10 minutes $[9,10,11,12]$. So far, these models rely on local and historical measurements which loose their informative value as the forecast lead time increases. In view of that limitation, a promising line of work is to explicitly determine and predict the sequence of regimes based on the information extracted from the weather radar observations, instead of assuming it hidden and estimating it from the wind time series itself. That way, combining weather radar observations and and statistical models is expected to fill in the gap between 2 consecutive meteorological forecasts and improve wind power predictability up to 2-3 hours, with the interesting potential of correcting for phase errors of NWP models when they occur. This approach meets many recent works in the sense that it focuses on a better exploitation of available observations rather than the development of more complex and overparametrized models. From the controller perspective, the issue is to adapt the wind farm control strategy with respect to the predicted wind power fluctuations [4]. There has been a recent increase of the attention for developing flexible controllers during extreme events, in order to find solutions for better planning of sudden wind farms shut downs [5].

\subsection{Limitations of weather radar data for wind power predictability}

In section 3, we reported a number of technical limitations that could reduce the informative power of weather radar data. These limitations are illustrated with examples from Radar@ Sea in Appendix A. In particular, we mentioned the importance of mitigating the effects of measurement artifacts for avoiding the generation of false alarms due to clutter 


\section{CONCLUSION}


severely degrade the accuracy of weather radar observations and, therefore, their usefulness in other applications [30].

This has led to a unilateral recommendation from the radar community for excluding wind farm sites in close proximity to radar installations [31]. In our view, this rather reflects the lack of coordination between the two communities. Eventually, benefits could be mutual and, not only could weather radars bring benefits to the wind energy community, their application in wind energy would also create new business opportunities and attract more attention for research and development on their techniques. For instance, light configuration weather radars, such as the LAWR used in Radar@Sea, are being tested as observational tools of the sea state, for measuring wave heights, in view of improving the planning of maintenance operations at offshore wind farms. Alternatively, weather radars are being used for monitoring bird migration and could provide important information in view of assessing the potential impact of wind farms on bird populations.

Finally, Radar@Sea places focus on the application of weather radars in offshore environments because it is where the largest potential is foreseen, especially, for wind farms for which no upwind information is available. However, weather radar could also be very useful for onshore applications and, particularly, for the detection and correction of phase errors. For instance, mid-latitude squall lines often develop ahead of cold fronts and propagate both over water and land. Tracking squall lines could therefore be useful for assessing the good phasing of meteorological forecasts generated with NWP models.

\section{ACKNOWLEDGEMENT}

This work was fully supported by the Danish Public Service Obligation (PSO) fund under the project "Radar@Sea" (contract PSO 2009-1-0226) which is gratefully acknowledged. DONG Energy and Vattenfall are acknowledged for sharing the images generated by the LAWR and the wind data for the Horns Rev 1 wind farm, respectively. DHI is thanked for providing assistance with the images. The authors also express their gratitude to the radar meteorologists from the Danish Meteorological Institute (DMI) for providing data from the Rømø radar and sharing their expertise. Finally, we thank Roland Löwe for his constructive comments for improving the present manuscript. 


\section{A. DATA QUALITY CONTROL}

\section{A.1. Sea clutter}

We start by analyzing the effects of the removal of the mechanical clutter fence on the LAWR images. It resulted in a recurrent and widespread sea clutter during the first six months of the data collection campaign, from April to September 2010. For this analysis, we use the original images in polar coordinates because sea clutter is usually azimuth dependent. The polar images are $360 \times 500$ and each pixel takes an Integer value between 0 and 1023. Images displaying no precipitation echoes were collected and averaged over time in order to produce a clutter map. For each of the 360 sampled azimuths, there is a systematic bias in the form of a positive and linear relationship between the count values generated by the LAWR and their range. This problem is illustrated in Figure 9(a) where that relationship is shown for observations sampled in 3 different azimuths. One can notice that many data points lay apart from the lower trend, for all azimuths. They correspond to pixels that are recurrently affected by ground clutter and are identified in a subsequent step, after correcting for the trend. Correcting for systematic and non random artifacts is very important as many weather radar imagery techniques make use of heuristics which are not robust to such artifacts (e.g., thresholding operations to define "wet" and "dry" pixels). In addition, the level of uncertainty introduced by ground clutter contamination varies from one azimuth to another. To estimate the relationship between the count values and its range, we propose a linear regression model for each of the 360 azimuths as follows:

$$
Y^{(i)}=\theta_{0}^{(i)}+\theta_{1}^{(i)} X+\varepsilon^{(i)}, \quad i=1, \ldots, 360
$$

where $Y^{(i)}=\left(Y_{1}^{(i)}, \ldots, Y_{n}^{(i)}\right)^{T}$ is a vector of $n$ counts values extracted from the $i^{t h}$ azimuth of the clutter map, $X$ is the range, $\varepsilon^{(i)}$ is a random variable which is assumed normally distributed with zero mean and standard deviation $\sigma^{(i)}$, and $\Theta^{(i)}=\left(\theta_{0}^{(i)}, \theta_{1}^{(i)}\right)^{T}$ the vector of unknown parameters to be estimated for each azimuth $i$. For this model, a widely used estimator is the Least Squares (LS) estimator which is obtained by minimizing the sum of squared residuals, as follows:

$$
\begin{gathered}
\widehat{\Theta}=\underset{\Theta}{\operatorname{argmin}} S(\Theta) \\
\text { with } S(\Theta)=\sum_{j=1}^{n}\left(Y_{j}^{(i)}-\theta_{0}^{(i)}-\theta_{1}^{(i)} X_{j}\right)^{2}=\sum_{j=1}^{n}\left(\varepsilon_{j}^{(i)}\right)^{2}
\end{gathered}
$$


However, it is a well-known issue that the LS estimator is not robust to extreme values or outliers, often resulting in a poor fit of the data. Here, to overcome that problem, we use a robust technique based on the Least Trimmed Squares (LTS) [45]. The advantage of using such technique is that it can resist up to $50 \%$ of data points laying apart of the main trend. So, instead of minimizing the sum of squared residuals as in the LS technique, we minimize the sum of the $k$ smallest squared residuals, as follows:

$$
\begin{gathered}
\qquad(\Theta)=\sum_{j=1}^{k}\left(\varepsilon^{(i)^{2}}\right)_{j: n} \\
\text { with } k=\alpha n+1 \text { and } 0.5<\alpha<1
\end{gathered}
$$

where $\left(\varepsilon^{(i)^{2}}\right)_{1: n}<\ldots<\left(\varepsilon^{(i)^{2}}\right)_{n: n}$ are the ordered squared residuals, sorted in ascending order. $(1-\alpha)$ corresponds to the percentage of outliers that the method is assumed to resist and it cannot exceed $50 \%$. $(1-\alpha)$ is directly related to the notion of breakdown point which is the smallest percentage of outliers than can cause large deviations of the estimates. An example of the respective performances of the LS and LTS regressions is given in Figure 9(b). It can be observed that the LS regression is clearly not suitable for such problem. In contrast, the LTS regression performs equally well for all azimuths. In this application of the LTS regeression, we set $\alpha=0.4$. We assumed the sea clutter to be additive and, for each image and azimuth, we subtracted the fitted trend from the original measurements.

\section{A.2. Ground clutter}

Mitigating ground clutter on weather radar images remains a complex process and is best to be performed on the original measurements at different elevations since clutter echoes are usually limited to the lower elevations [46]. In addition, Doppler radars can take advantage of the reflected Doppler speed to discriminate between clutter which is usually caused by non-moving targets (buildings, mountains, etc) and precipitation which is driven by the wind. In practise, ground clutter translates into non-precipitation or non-meteorological targets having high reflectivity values which may be mistaken for small storm cells. The difficulty in identifying and correcting clutter echoes arises when ground clutter is embbeded or contiguous to precipitation fields. Ground clutter has a specific statistical signature, it is stationary in space. However, it may not be stationary over time and the values of pixels affected by clutter may vary with the weather conditions.

Here, we focus on recurrent ground clutter problems which were not detected by clutter removal filters applied on the original measurements before producing the final images [32,33]. We follow the method proposed in [47] which is well suited for that problem since it is based on the assumption that clutter is spatially stationary. It formulates the identifaction 
- automatic and unsupervised, leading to a data-driven determination of the threshold, depending on the level of clutter contamination;

- computationally cheap;

- robust since based on count statistics.

The outline of the method is as follows:

- for each of the $N$ pixels $(x, y)$ of the image, compute the frequency $f_{(x, y)}(\tau)$ of its value exceeding a given threshold $\tau$ over a period of time $T$. In particular, a frequency value close to 1 likely indicates a clutter.

- compute a histogram by binning the $N$ frequency $f_{(x, y)}(\tau)$ values into $L$ levels. Let $p_{i}$ be the proportion of pixels at level $i$, for $i=1, \ldots, L$.

- use the segmentation method proposed in [48] for determining a consistent threshold value $k^{*}$ which separates the pixel population into 2 groups, with the first group $G_{1}$ likely being clutter free and the second group $G_{2}$ likely bieng affected by clutter. The method consists in an iterative search for the optimal threshold $k^{*}$ by maximizing the inter-group variance $\sigma_{B}^{2}(k)$ :

$$
\begin{aligned}
& k^{*}=\underset{1<k<L}{\operatorname{argmax}} \sigma_{B}^{2}(k) \\
& \text { with } \quad \sigma_{B}^{2}(k)=w_{1} w_{2}\left(\mu_{2}-\mu_{1}\right)^{2} \\
& w_{1}=\sum_{i=1}^{k} p_{i} \text { and } w_{2}=\sum_{i=k+1}^{L} p_{i}=1-w_{1} \\
& \mu_{1}=\frac{1}{w_{1}} \sum_{i=1}^{k} i p_{i} \text { and } \mu_{2}=\frac{1}{w_{2}} \sum_{i=k+1}^{L} i p_{i}
\end{aligned}
$$

where $w_{1}$ and $w_{2}$ are the respective probability of occurence of $G_{1}$ and $G 2$, while $\mu_{1}$ and $\mu_{2}$ are their respective mean level.

Note that one of the inherent hypothesis of the method described hereabove, is that the histogram to be thresholded is bimodal, implying thus that there is a significant fraction of pixels affected by clutter, at any time. This idea matches with the recurrent clutter we aim at identifying. However, clutter is non stationary over time and some pixels may be clutter over some periods of time and clutter free over some others. In order to account for that feature, the procedure is applied on a rolling window of 24 hours (i.e., 1440 images for the LAWR) and moved forward along the acquisition of new images. All 
images are used, both those with and without precipitation echoes. An example is given in Figure 10(a) which shows an image generated by the LAWR before and after the removal of recurrent clutter. The original threshold $\tau$ was determined by experience to reflect the limit between precipitation and non-precipitation targets, Here, we used $\tau=5$. However, this method does not account for contiguity features, disregarding the potential cluster effect of clutter. A potential line of work for further improving that method could be to refine the segmentation process with a Markov Random Field [49] step for taking into account potential spatial correlation between neighboring pixels. As for now, the method was implemented as presented in [47] and satisfactory results were obtained. The values of single clutter pixels (i.e., a pixel is clutter whereas its 8 neighbours are clutter free) were interpolated with the median of its 8 neighbours. For large clusters of clutter pixels, no attempt was made to interpolate them and their values set to 0 .

\section{A.3. Potential underestimation of near surface precipitation at far ranges}

Among the inherent limitations of long range weather radars listed in section 3, we mentioned the potential underestimation of near surface precipitation. An illustrative example of this problem is given in Figure 11. Figure 11(a) depicts the theoretical relationship between the ground height of the 9 elevation scans of the Rømø radar with respect to the radar range, under normal wave refractivity conditions in the atmosphere. While the 9 elevation scan strategy enables an efficient sampling of the atmosphere, one can notice that near surface precipitation, within a $2 \mathrm{~km}$ height above ground level, cannot be detected at ranges farther than $150-180 \mathrm{~km}$, due to the curvature of the Earth (elevation $0^{\circ}$ ). This limitation is further demonstrated in Figure 11(b) which shows how it translates on a precipitation reflectivity image from September 17, 2010. One can see that the weather radar detects precipitation in the close ranges $(<150 \mathrm{~km})$ but looses its observational power at farther ranges because of precipitation fields developing in low altitudes. That limitation can be seen as the consequence of the physical settings of some meteorological phenomena described in section 2. For instance, open cellular convection phenomena develop within 1-2 km of the planetary boundary layer and are capable of producing precipitation. In such case, the visibility the Rømø radar offers is likely to be reduced as illustrated in Figure 11.

\section{A.4. Other limitations}

Other limitations or problems enountered by weather radars include anomalous propagation and partial beam-filling. They can well be detected but are more difficult to correct. Partial beam filling is a limitation that occur when the vertical distribution of precipitation fields is not uniform over the volume scanned by the radar. This problem is illustrated in Figure 12(a). It can be seen that precipitation close to the radar (i.e., in the center of the image) have higher count values than precipitation sampled far from it. In that example, precipitation is low-lying, widespread and relatively uniform 
along the radar range. However, as the radar beam propagates downstream, through the atmosphere, the volume scanned increases. The amount of precipitation detected at close ranges, relatively to the volume scanned, is therefore larger than at far ranges. Ongoing research is carried out in order to retrieve the altitude of precipitation and improve beam-filling correction procedures [32].

Another problem that affects radar observational accuracy is known as anomalous propagation. An example of how it appears on weather radar images is given in Figure 12(b). It shows echoes likely caused by super-refraction of the radar beam. These echoes falsely indicate the detection of precipitation. It often occurs when there is a temperature inversion in the atmosphere, warm and moist air overlaying cool air. In Denmark, these situations are typical during the summer with southerly winds which bring moist continental air. In contrast to ground clutter, anomalous propagation is not characterized by a strong spatial stationarity. Furthermore, it may even grow and decay in the same way as light precipitation systems which makes it difficult to detect in an automated fashion.

\section{REFERENCES}

1. Future offshore wind power sites - 2025. Danish Energy Agency, Ministry of Climate and Energy 2007; (ISBN: 978-87-7844-677-0).

2. Sempreviva A, Barthelmie R, Pryor S. Review of methodologies for offshore wind resource assessment in European seas. Surveys in Geophysics 2008; 29:471-497.

3. Sørensen P, Cutululis AN, Vigueras-Rodriguez A, Jensen L, Hjerrild J, Donovan M, Madsen H. Power fluctuations from large wind farms. IEEE Transactions on Power Systems 2007; 22:958-965.

4. Kristoffersen J. The Horns Rev wind farm and the operational experience with the wind farm main controller. In Proceedings of the Offshore Wind International Conference and Exhibition, Copenhagen, Denmark 2005.

5. Cutululis AN, Detlefsen N, Sørensen P. Offshore wind power prediction in critical weather conditions. In Proceedings of the $10^{\text {th }}$ International Workshop on Large-Scale Integration of Wind Power into Power Systems, Aarhus, Denmark 2011.

6. Akhmatov V, Rasmussen C, Eriksen PB, Pedersen J. Technical aspects of status and expected future trends for wind power in Denmark. Wind Energy 2007; 10:31-49.

7. Jones L, Clark C. Wind integration - A survey of global views of grid operators. In Proceedings of the $10^{\text {th }}$ International Workshop on Large-Scale Integration of Wind Power into Power Systems, Aarhus, Denmark 2011.

Wind Energ. 2012; 00:2-40 @ 2012 John Wiley \& Sons, Ltd. 
8. Giebel G, Brownsword R, Kariniotakis G, Denhard M, Draxl C. The state-of-the-art in short-term prediction of wind power: A literature overview. Technical Report, ANEMOS.plus 2011.

9. Pinson P, Christensen L, Madsen H, Sørensen P, Donovan M, Jensen L. Regime-switching modelling of the fluctuations of offshore wind generation. Journal of Wind Engineering and Industrial Aerodynamics 2008; 96:23272347.

10. Trombe P, Pinson P, Madsen H. A general probabilistic forecasting framework for offshore wind power fluctuations. Energies 2012; 5:621-657.

11. Pinson P. Very short-term probabilistic forecasting of wind power time-series with generalized Logit-Normal distributions. Journal of the Royal Statistical Society, Series C 2011; Available online.

12. Gallego C, Pinson P, Madsen H, Costa A, Cuerva A. Influence of local wind speed and direction on wind power dynamics - Application to offshore very short-term forecasting. Applied Energy 2011; 88:4087-4096.

13. Vincent C, Pinson P, Giebel G. Wind fluctuations over the North Sea. International Journal of Climatology 2010; 31:1584-1595.

14. Lakshmanan V, Smith T, Stumpf G, Hondl K. The warning decision support system-integrated information. Weather and Forecasting 2007; 22:596-612.

15. Cappelen J, Jørgensen B. Observed wind speed and direction in Denmark - with climatoligical standards normals, 1961-90. Technical Report, DMI - Danmarks Meteorologiske Institut 1999.

16. Van Delden A. The synoptic setting of thunderstorms in Western Europe. Atmospheric Research 2001; 56:89-110.

17. Akhmatov V. Influence of wind direction on intense power fluctuations in large offshore windfarms in the North Sea. Wind Engineering 2007; 31:59-64.

18. Vincent C, Hahmann A, Kelly M. Idealized mesoscale model simulations of open cellular convection over the sea. Boundary-Layer Meteorology 2012; 142:103-121.

19. Atkinson B, Zhang J. Mesoscale shallow convection in the atmosphere. Reviews of Geophysics 1996; 34:403-431.

20. International Energy Agency. State of the art of remote wind speed sensing techniques using Sodar, Lidar and satellites. $51^{s} t$ IEA Topical Expert Meeting, 2007. Available online: www.ieawind.org.

21. Harris M, Hand M, Wright A. Lidar for turbine control. National Renewable Energy Laboratory, NREL/TP-50039154, Golden, CO, Tech. Rep 2006.

22. Mikkelsen T, Hansen K, Angelou N, Sjöholm M, Harris M, Hadley P, Scullion R, Ellis G, Vives G. Lidar wind speed measurements from a rotating spinner. In Proceedings of the European Wind Energy Conference and Exhibition, 
Warsaw, Poland 2010.

23. Hasager C, Peña A, Christiansen M, Astrup P, Nielsen M, Monaldo F, Thompson D, Nielsen P. Remote sensing observation used in offshore wind energy. IEEE Journal of Selected Topics in Applied Earth Observations and Remote Sensing 2008; 1:67-79.

24. Marshall J, Palmer W. The distribution of raindrops with size. Journal of Atmospheric Sciences 1948; 5:165-166.

25. Meischner P. Weather radar: Principles and advanced applications. Springer, 2004.

26. Serafin R, Wilson J. Operational weather radar in the United States: Progress and opportunity. Bulletin of the American Meteorological Society 2000; 81:501-518.

27. Holleman I, Delobbe L, Zgonc A. Update on the European weather radar network (OPERA). Proceedings of the $5^{\text {th }}$ European Conference on Radar in Meteorology and Hydrology, Helsinki, Finland 2008.

28. Crum T, Alberty R. The WSR-88D and the WSR-88D operational support facility. Bulletin of the American Meteorological Society 1993; 74:1669-1688.

29. Bøvith T. Detection of weather radar clutter. PhD Thesis, Department of Informatics and Mathematical Modelling, Technical University of Denmark, Kgs. Lyngby 2008. (ISBN: 87-643-0436-1).

30. Isom B, Palmer R, Secrest G, Rhoton R, Saxion D, Allmon T, Reed J, Crum T, Vogt R. Detailed observations of wind turbine clutter with scanning weather radars. Journal of Atmospheric and Oceanic Technology 2009; 26:894-910.

31. Chèze J, Haase G. Impact study on radar observations by wind turbines - OPERA deliverable: OPERA-2010-05. Technical Report, EUMETNET 2010.

32. Pedersen L, Jensen N, Madsen H. Calibration of Local Area Weather Radar - Identifying significant factors affecting the calibration. Atmospheric Research 2010; 97:129-143.

33. Gill R, Overgaard S, Bøvith T. The Danish weather radar network. In Proceedings of the $4^{t} h$ European Conference on Radar in Meteorology and Hydrology, Barcelona, Spain 2006.

34. Lakshmanan V. Image processing of weather radar reflectivity data: Should it be done in Z or dBZ? Electronic Journal of Severe Storms Meteorology 2012; 7:1-8.

35. Biggerstaff M, Listemaa S. An improved scheme for convective/stratiform echo classification using radar reflectivity. Journal of Applied Meteorology 2000; 39:2129-2150.

36. Houze Jr R. Mesoscale convective systems. Reviews of Geophysics 2004; 42.

37. Jirak I, Cotton W, McAnelly R. Satellite and radar survey of mesoscale convective system development. Monthly Weather Review 2003; 131:2428-2449.

Wind Energ. 2012; 00:2-40 (C) 2012 John Wiley \& Sons, Ltd. 
Weather Radars - The new eyes for offshore wind farms?

P.-J. Trombe et al.

38. Baldwin M, Kain J, Lakshmivarahan S. Development of an automated classification procedure for rainfall systems. Monthly Weather Review 2005; 133:844-862.

39. Tuttle J, Foote G. Determination of the boundary layer airflow from a single Doppler radar. Journal of Atmospheric and Oceanic Technology 1990; 7:218-232.

40. Laroche S, Zawadzki I. Retrievals of horizontal winds from single-Doppler clear-air data by methods of cross correlation and variational analysis. Journal of Atmospheric and Oceanic Technology 1995; 12:721-738.

41. Ghil M, Malanotte-Rizzoli P. Data assimilation in meteorology and oceanography. Advances in Geophysics 1991; 33:141-266.

42. Dance S. Issues in high resolution limited area data assimilation for quantitative precipitation forecasting. Physica D: Nonlinear Phenomena 2004; 196:1-27.

43. Zhao Q, Cook J, Xu Q, Harasti P. Using radar wind observations to improve mesoscale numerical weather prediction. Weather and Forecasting 2006; 21:502-522.

44. Dixon M, Wiener G. TITAN: Thunderstorm Identification, Tracking, Analysis, and Nowcasting - A Radar-based Methodology. Journal of Atmospheric and Oceanic Technology 1993; 10:785-797.

45. Rousseeuw P. Least median of squares regression. Journal of the American Statistical Association 1984; 79:871-880.

46. Steiner M, Smith J. Use of three-dimensional reflectivity structure for automated detection and removal of nonprecipitating echoes in radar data. Journal of Atmospheric and Oceanic Technology 2002; 19:673-686.

47. Lakshmanan V, Zhang J, Hondl K, Langston C. A statistical approach to mitigating persistent clutter in radar reflectivity data. IEEE Journal on Selected Topics in Applied Earth Observations and Remote Sensing 2012; Available online.

48. Otsu N. A threshold selection method from gray-level histograms. Automatica 1975; 11:285-296.

49. Li S. Markov Random Field modeling in image analysis. Springer, 2009. 
Table I. Weather types and their associated precipitation patterns in Denmark, as described in [15].

- They bring warm continental air

- Moist air transforms into heavy rain showers (and strong wind downdrafts),

- Occasional thunderstorms.

- Westerly winds bring depressions associated with frontal systems and trailing precipitation (occasional snow in the winter) or heavy rain showers,

- Successive arrival of depressions may repeat over weeks, being separated by one or two days.

- Cold air carried out by fronts passing over warm sea often results in strong convection and rain showers.
- Under westerly winds, precipitation are usually more abundant in the summer than in the winter. 
Table II. Geographic information, technical specifications and operational settings of the two weather radars used in the Radar@Sea experiment.

\begin{tabular}{|c|c|c|c|}
\hline & & LAWR (X-Band) & Rømø (Doppler C-Band) \\
\hline \multirow{4}{*}{ 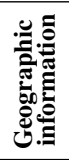 } & Location & Offshore (HR2) & Onshore $(\mathrm{R} ø \mathrm{~m} \emptyset)$ \\
\hline & Coordinates & $55.600^{\circ} \mathrm{N}, 7.623^{\circ} \mathrm{E}$ & $55.173^{\circ} \mathrm{N}, 8.552^{\circ} \mathrm{E}$ \\
\hline & Distance to HR1 & $19 \mathrm{~km}$ & $57 \mathrm{~km}$ \\
\hline & Height (above sea level) & $30 \mathrm{~m}$ & $15 \mathrm{~m}$ \\
\hline \multirow{7}{*}{ 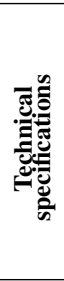 } & Frequency & $9.41 \mathrm{GHz}$ & $5.62 \mathrm{GHz}$ \\
\hline & Wavelength & $3.2 \mathrm{~cm}$ & $5.4 \mathrm{~cm}$ \\
\hline & Vertical opening angle & $\pm 10^{\circ}$ & $\pm 1^{\circ}$ \\
\hline & Horizontal opening angle & $\pm 1^{\circ}$ & $\pm 1^{\circ}$ \\
\hline & Scanning strategy & Continuous & 9 elevations \\
\hline & Scanning elevation & - & $0.5^{\circ}, 0.7^{\circ}, 1^{\circ}, 1.5^{\circ}, 2.4^{\circ}$ \\
\hline & & & $4.5^{\circ}, 8.5^{\circ}, 13^{\circ}, 15^{\circ}$ \\
\hline \multirow{4}{*}{ 吾 } & Image frequency & $1 \mathrm{~min}$. & $10 \mathrm{~min}$. \\
\hline & Range & $60 \mathrm{~km}$ & $240 \mathrm{~km}$ \\
\hline & Grid size & $500 \times 500 \mathrm{~m}$ & $2 \times 2 \mathrm{~km}$ \\
\hline & Data & $\begin{array}{c}\text { Dimensionless count } \\
\text { values (Integer 0-255) }\end{array}$ & $\begin{array}{l}\text { Decibel of reflectivity } \\
\text { (dBZ) }\end{array}$ \\
\hline
\end{tabular}




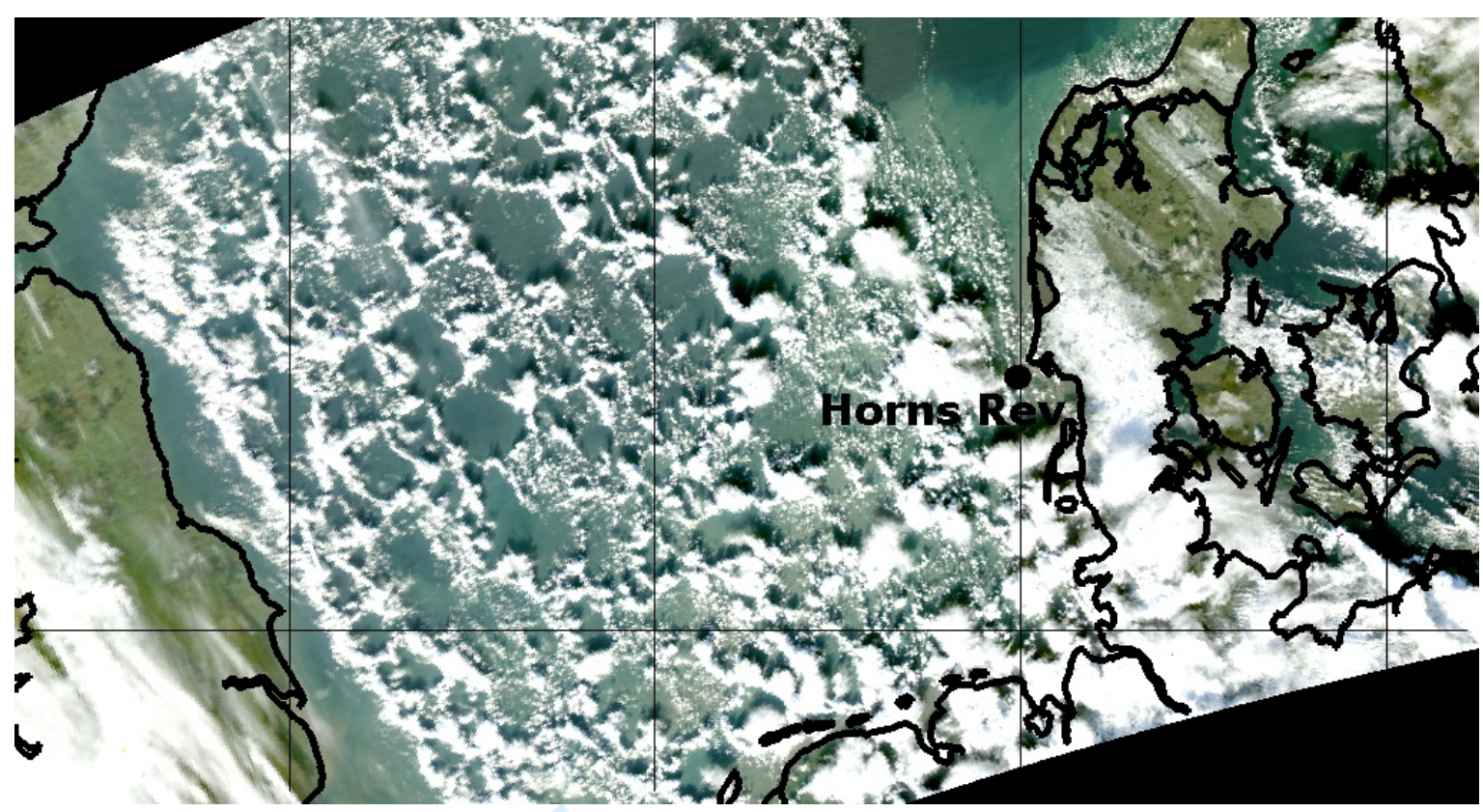

Figure 1. Satellite image of a case of open cellular convection over the North Sea. The cloud tops are shaped like a honeycomb, with cloud rings on the edge and cloud-free centers. The image is from the MODIS TERRA satellite: $h t t p: /$ ladsweb. nascom. nasa.

$$
\text { gov }
$$




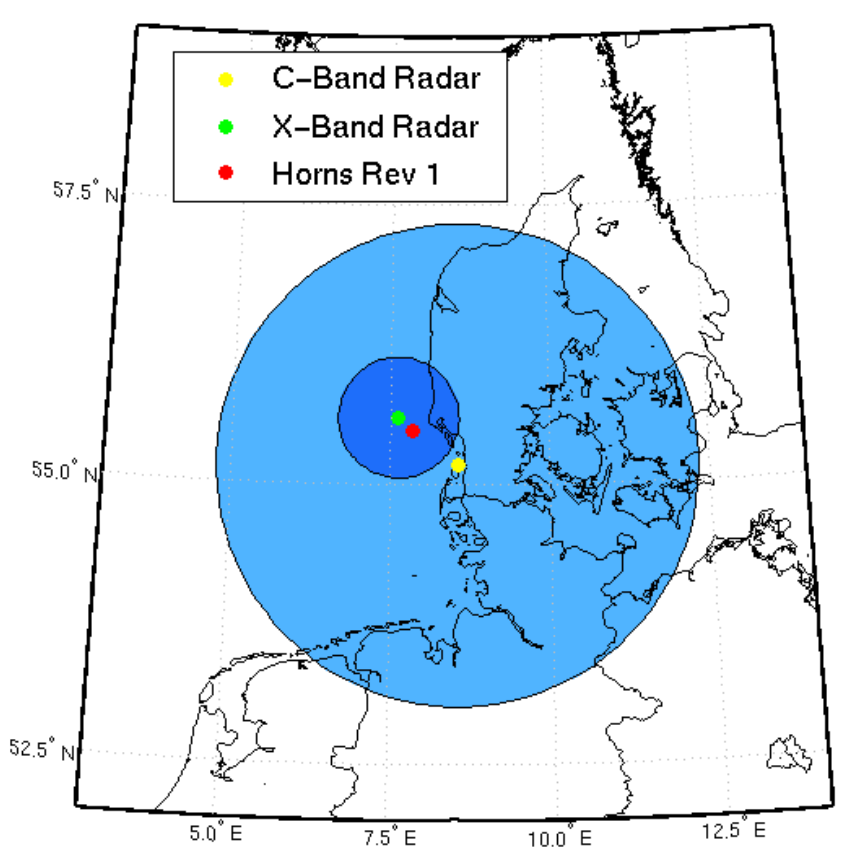

Figure 2. Geographical location of the X-Band radar (LAWR), the C-Band radar and the Horns Rev 1 wind farm, $20 \mathrm{~km}$ off the west coast of Jutland, Denmark. The area shaded in dark blue is the area covered by the X-band radar (range of $60 \mathrm{~km}$ ) whereas the area shaded in light blue is the area covered by the C-Band radar (range of $240 \mathrm{~km}$ ). 


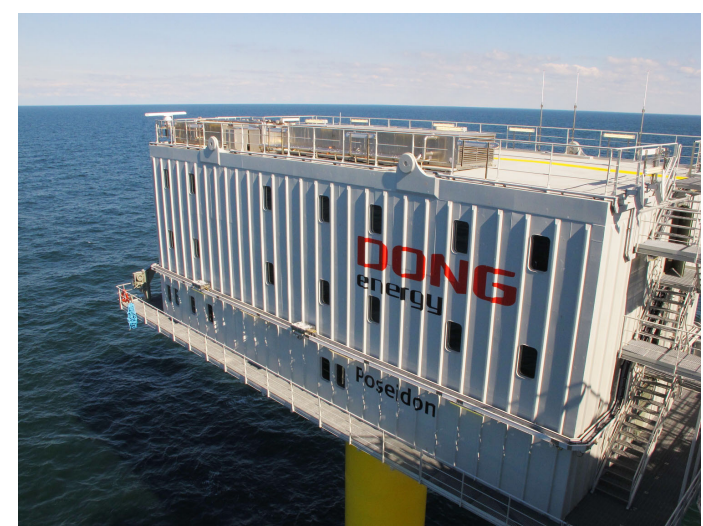

(a) Accommodation platform of the Horns Rev 2 wind farm. A LAWR can be seen on the top left corner of the platform.
Weather Radars - The new eyes for offshore wind farms?

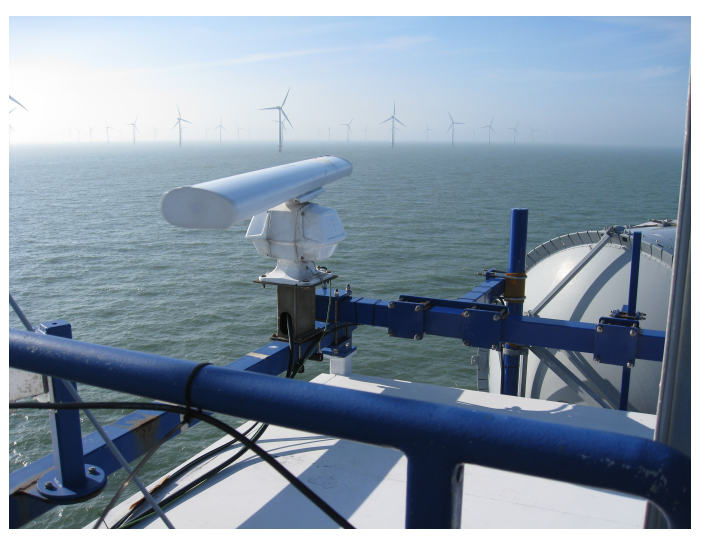

(b) Another LAWR is installed at the Horns Rev 1 wind farm for the needs of a separate experiment.

Figure 3. The first experiment of weather radars for offshore wind energy takes place at Horns Rev, Denmark. 


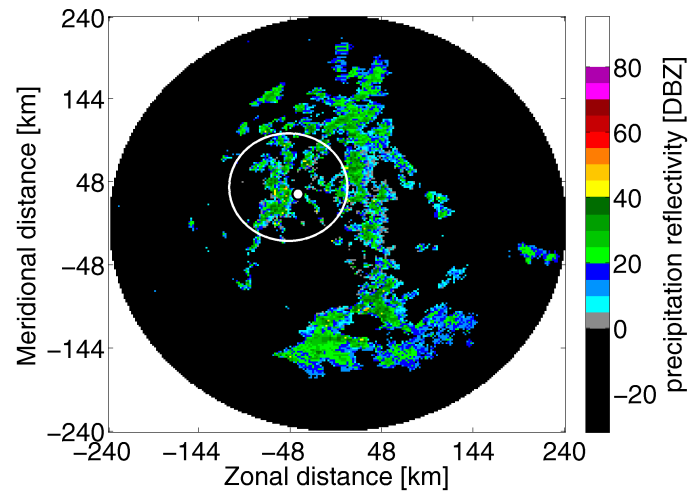

(a) Sample image generated by the Doppler C-Band weather radar.

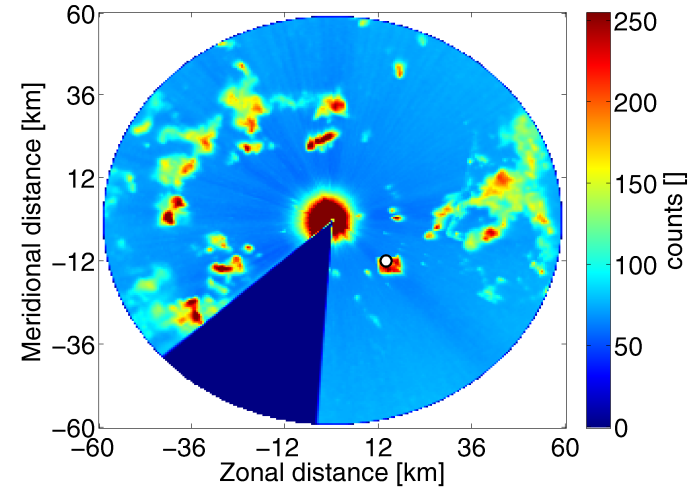

(b) Sample image generated by the LAWR.

Figure 4. Sample images generated by the two weather radars on August 29, 2010 at 3.30am. The white circle on Figure (a) indicates the area covered by the LAWR. The position of the Horns Rev 1 wind farm is depicted by a white dot on both images. As a result of their different scanning strategies, the 2 weather radars reveal different features of precipitation fields. 

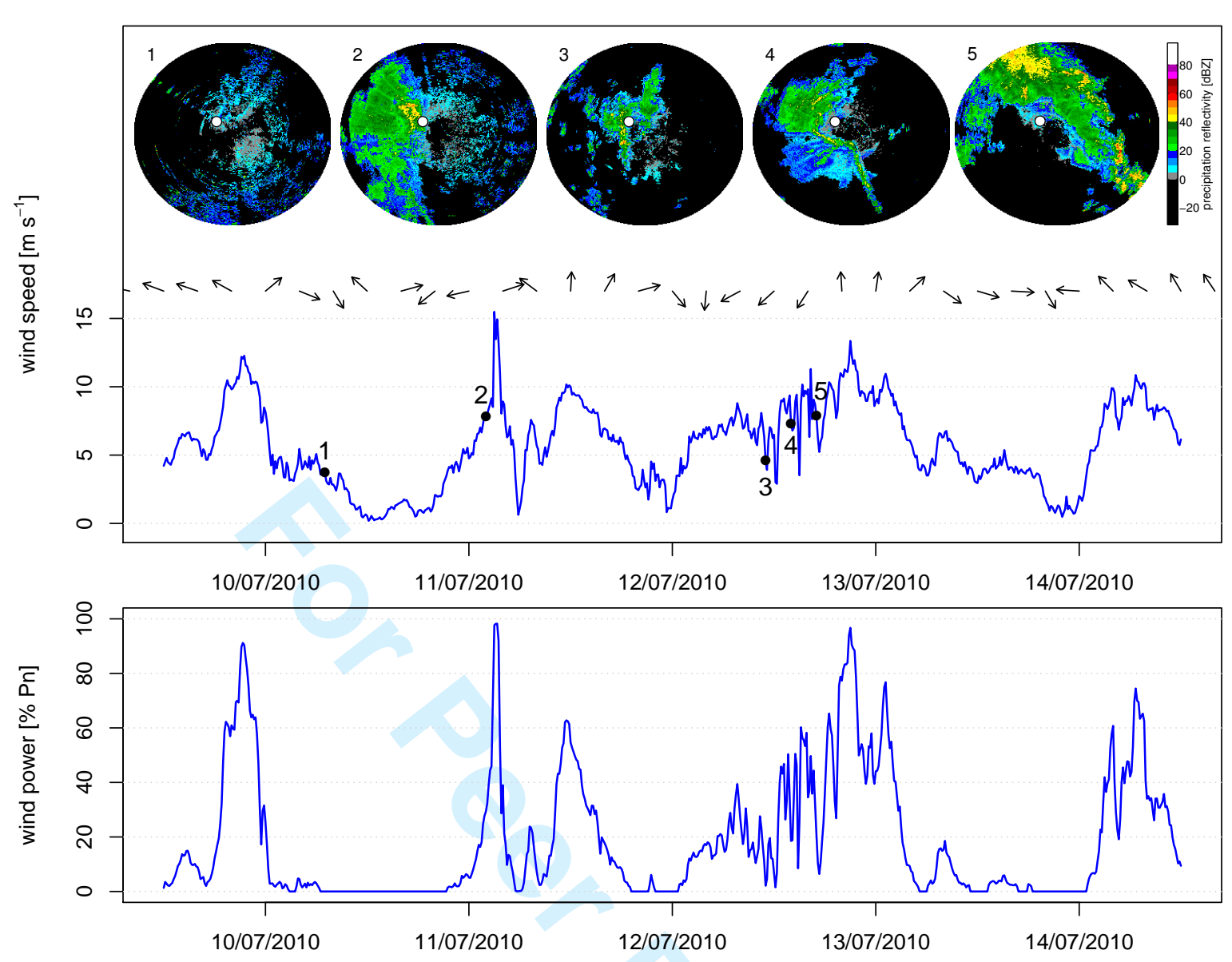

Figure 5. July 2010 - Typical summer storms bringing moist and warm air from the South, resulting in heavy rain showers. The images were generated by the C-Band radar in Rømø. The arrows indicate the wind direction recorded at HR1. (1) No precipitation but a case of anomalous propagation. (2) Development of a large convective rainfall system with an embedded storm just before a strong wind gust is sensed at the HR1 wind farm. (3-5) Development of another large storm associated with increased wind speed and wind power volatility at HR1. 

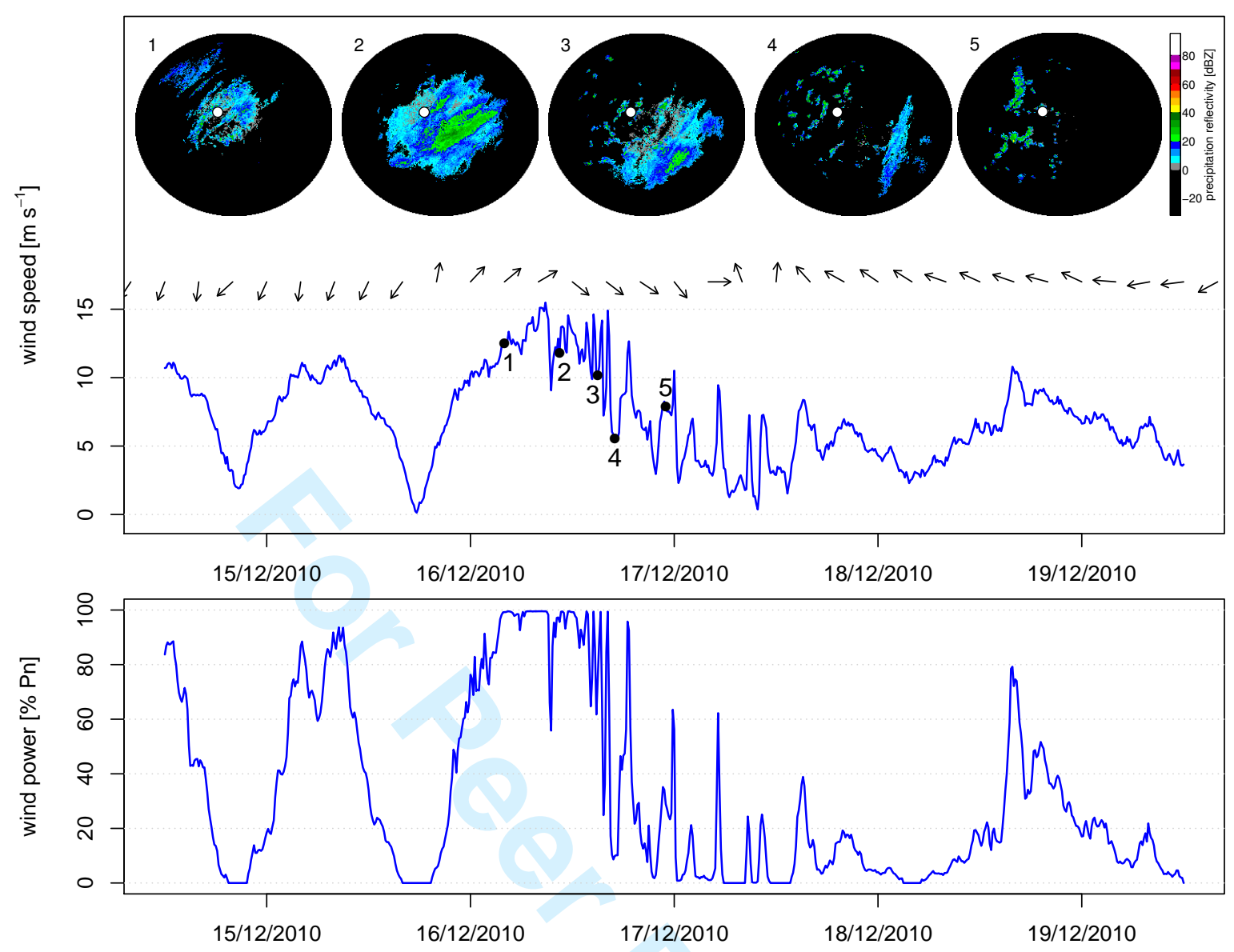

Figure 6. December 2010 - An example of cold front passage over the North Sea and the HR1 wind farm during the winter. The images were generated by the C-Band radar in Rømø. The arrows show the wind direction recorded at HR1. (1) The wind speed is peaking up with the arrival of the cold front. It leading edge is characterized by widespread stratiform precipitation with embedded convection. (2) A first large negative gradient of wind speed is sensed at HR1 while the leading edge of the cold front is passing across the wind farm. (3-5) Very large wind speed fluctuations coupled with a steady decrease of the mean wind speed. Small precipitating cells can be observed in the wake of that cold front. These cells correspond to well developed open cellular convection. 

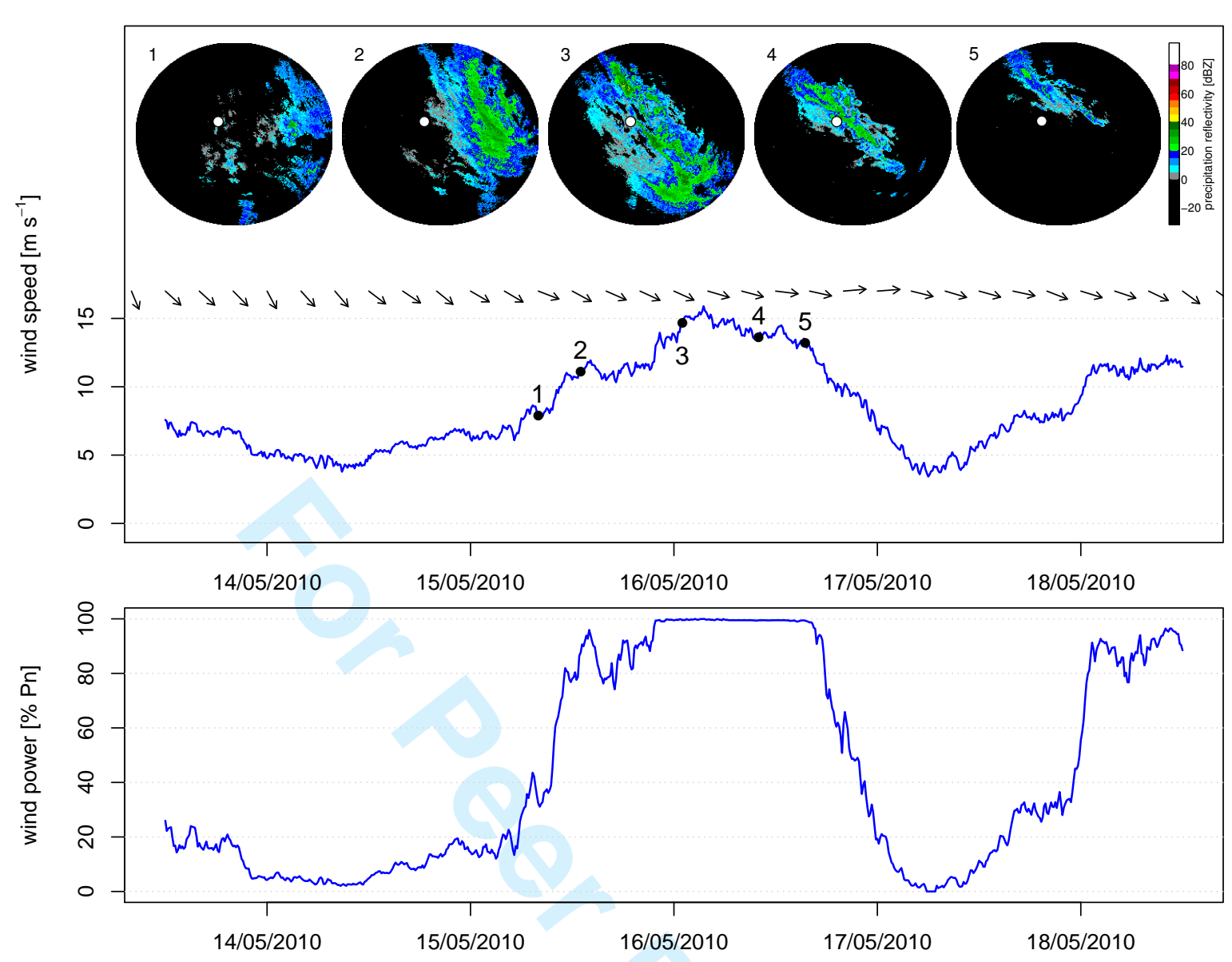

Figure 7. May 2010 - An example of precipitation system which is not associated with severe wind fluctuations at the HR1 wind farm. The images were generated by the C-Band radar in Rømø. The arrows show the wind direction recorded at HR1. (1-3) The wind speed increases steadily with the arrival of the precipitation system from the North-East. (4-5) The wind speed decreases steadily as the precipitation dissipates. 


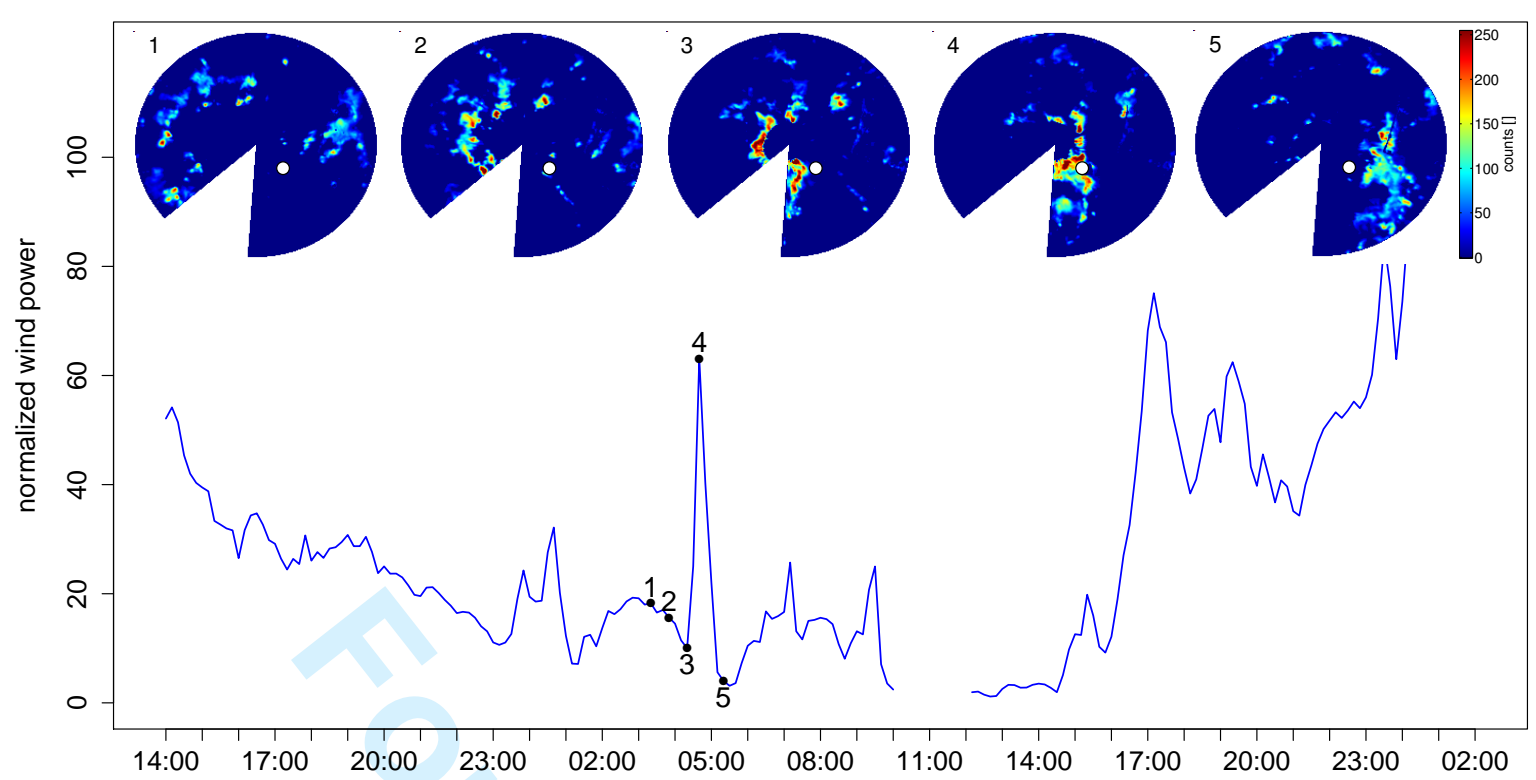

Figure 8. August 2010 - The passage of small precipitation cells through the Horns Rev 1 wind farm causes a large fluctuation of wind power. The mean wind is westerly. The images were generated by the LAWR installed at HR2. 
1

P.-J. Trombe et al.

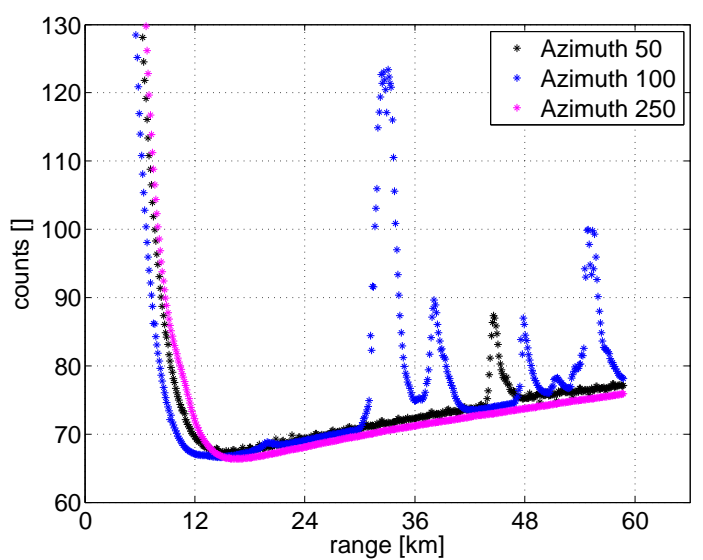

(a) Clutter map for azimuth 50,100 and 250. For each azimuth, and for range values between 12 and $60 \mathrm{~km}$, count values increase with respect to their range. Observations laying apart from the trend correspond to ground clutter.
Weather Radars - The new eyes for offshore wind farms?

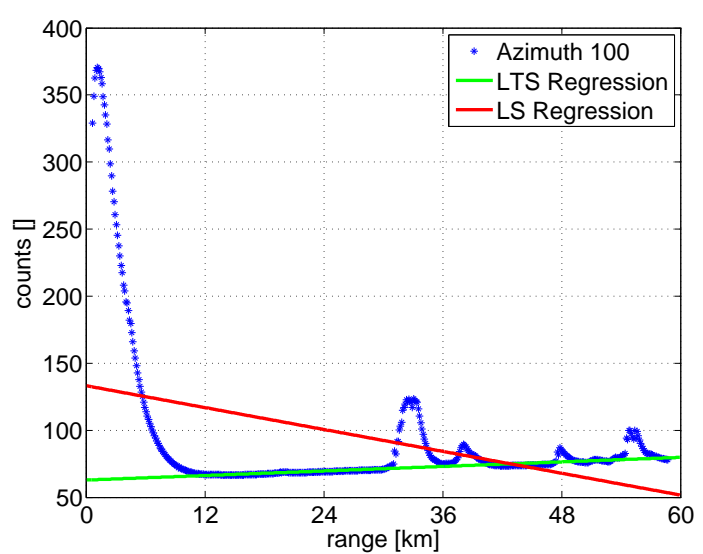

(b) Correcting for non random effects should preferably be performed with robust statistics. Here, we used the Least Trimmed Squares (LTS) regression because the estimator used in the Least Squares (LS) regression is not robust to outliers.

Figure 9. A clutter map is computed based on the original measurements in polar coordinates in order to remove the recurrent sea clutter contamination. A robust linear regression method is used for estimating the effects of the sea clutter on the images generated by the LAWR. 


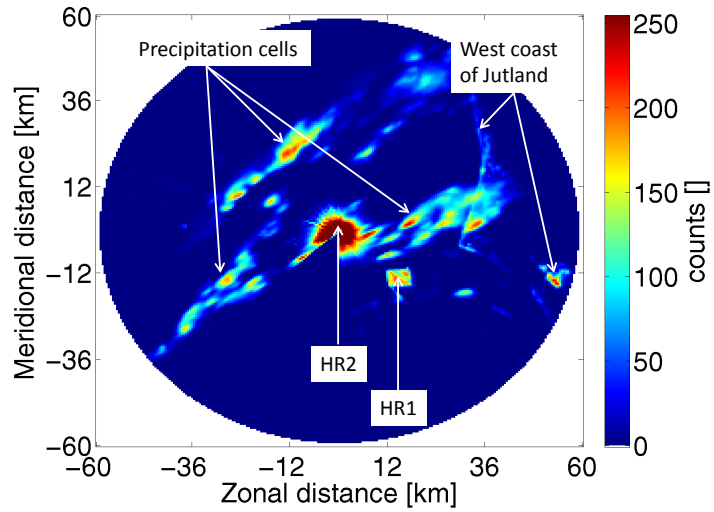

(a) Original image with precipitation and clutter.

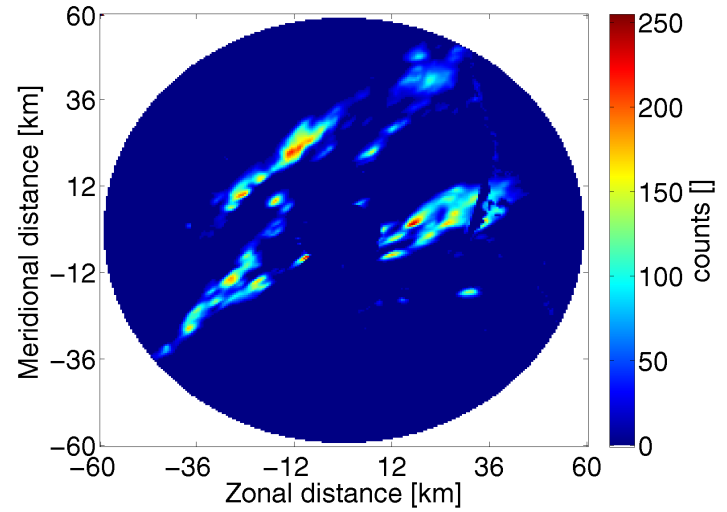

(b) Image after removing ground clutter.

Figure 10. Ground clutter is caused by the wind turbines of HR1 and HR2 and the West coast of Jutland, Denmark. Clutter translates into non-meteorological targets having high reflectivity values which may be mistaken for small storm cells and needs to be removed. 
1

2

3

4

5

6

7

8

9

10

11

12

13

14

15

16

17

18

19

20

21

22

23

24

25

26

27

28

29

30

31

32

33

34

35

36

37

38

39

40

41

42

43

44

45

46

47

48

49

50

51

52

53

54

55

56

57

58

59

60
P.-J. Trombe et al.

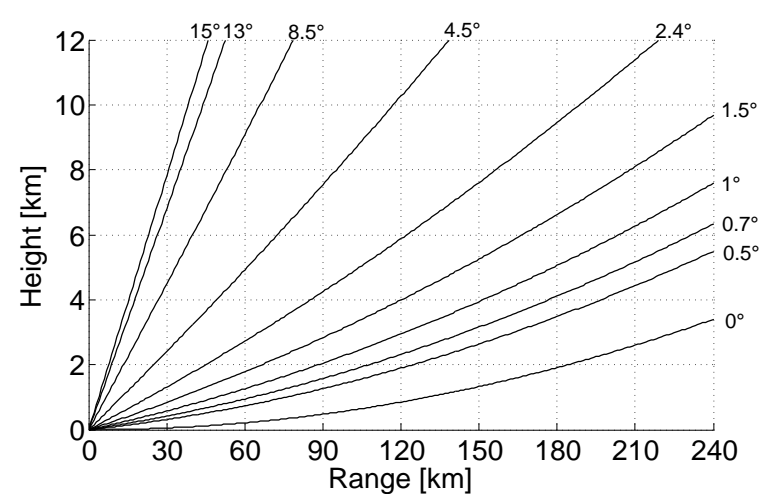

(a) Due to the curvature of the Earth, the height at which radar waves propagate increase with the range (here the 9 scan elevations of the C-band weather radar in $\mathrm{R} \emptyset \mathrm{m} \varnothing)$.
Weather Radars - The new eyes for offshore wind farms?

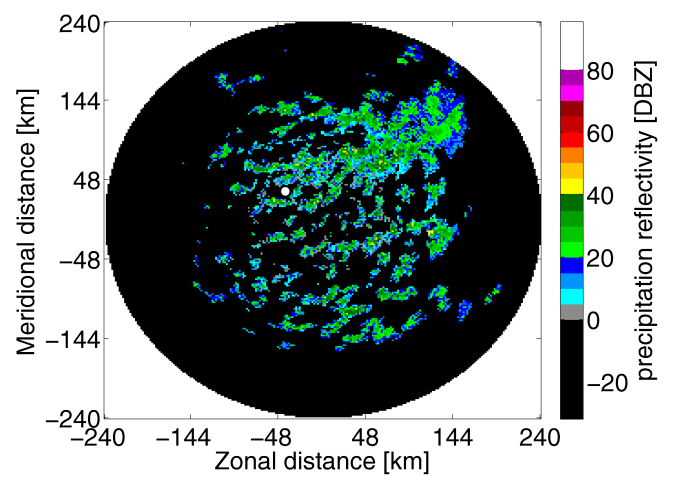

(b) Image on September 17, 2010 generated by the Rømø radar.

Figure 11. A typical example of the inherent limitation of long range weather radars for observing near surface precipitation. In particular, precipitation located within a $2 \mathrm{~km}$ height above ground level cannot be detected at ranges farther than $150-180 \mathrm{~km}$. 


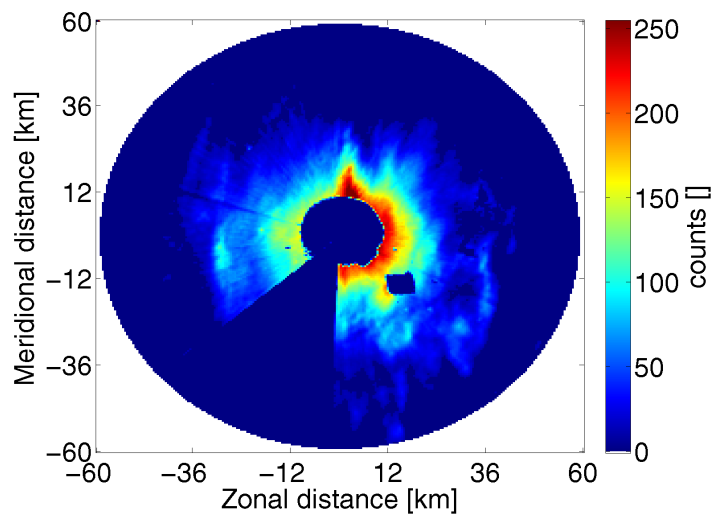

(a) Partial beam-filling on the LAWR on May 12, 2010 at 13:00. The volume scanned increases with the range. It results in close range precipitation being better sampled than precipitation at far ranges.

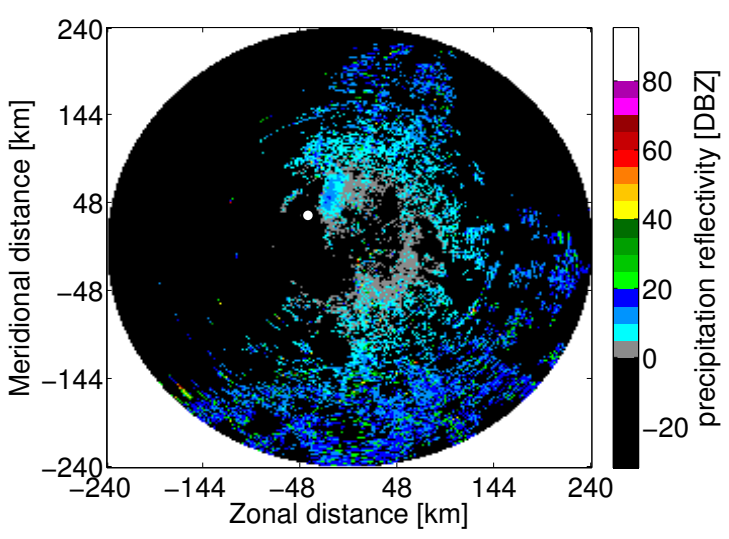

(b) Example of anamalous propagation on the Rømø radar, on July 7, 2010 at $05: 40$. The beam of the radar is bent towards the sea and the ground, and falsely indicates the presence of precipitation.

Figure 12. Examples of other limitations and problems encountered by weather radars. 